\title{
Debridement Ability of TruNatomy, S-One Plus, and Other Single File Systems
}

\author{
Duaa Waleed*(iD), Bahar Jaafar Selivany \\ Department of Conservative Dentistry, College of Dentistry, University of Duhok, Duhok, Iraq
}

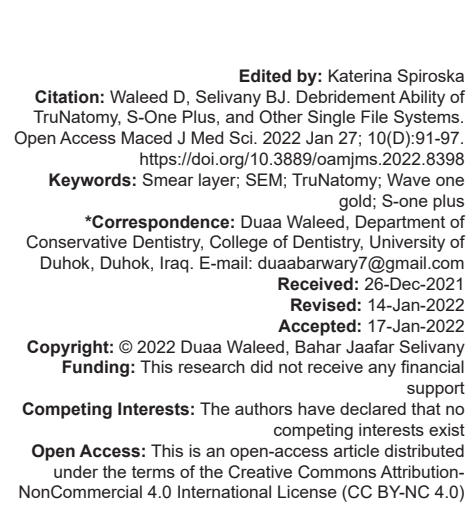

\section{Introduction}

A biomechanical debridement of the root canal system is required during the root canal instrumentation, which combines mechanical instrumentation with chemical disinfection to eradicate the majority of infective micro-organisms, as well as inorganic contaminant debris and dentin, from the root canal system. Cleaning and shaping the root canal system not only removes micro-organisms but permits better adaptation of the filling material, also enhances the action of irrigants and intracanal medicaments [1], [2], [3].

The invention and diversification of multiple rotary nickel-titanium file systems, characterized by super-elasticity and employed under well-defined torque and speed values, as well as diverse types of rotary movement (constant, reciprocal) were used to achieve this goal, to produce a tapered root canal with minimal chance of the original canal being transported and improves its cleaning and shaping ability [4], [5].

When rotary or hand files are used in root canals, a significant amount of debris and a smear layer are commonly produced. Any material left between the canal wall and the root canal filling may prevent intimate adaptation between them and may provide space for bacterial leakage and proliferation [6]. Dentin particles, remnants of living or necrotic pulp tissues, bacterial components, and retained irrigants make up the smear layer, which is a 1 to $2 \mu \mathrm{m}$ thick surface coating [7]. The smear layer is a "muddy" layer, whereas the surface debris has a "dusty" pattern [8]. Debris and smear layer were regarded as criteria to evaluate the cleaning ability.

TruNatomy heat-treated $\mathrm{NiTi}$ instruments (TRN; Dentsply Sirona) were recently created and are available in three sizes: small; size 20, 0.04 taper, prime; size 26, 0.04 taper, and medium; size 36, 0.03 taper. The TRN instrument has a slip shaping feature that allows for more debridement space, as well as being more flexible and fatigue resistant due to a specific heat treatment and design [9].

ProTaper Next (Dentsply Sirona, Ballaigues, Switzerland) is made of M-wire premanufacturing heat treatment technology with a rectangular asymmetric cross section, variable taper PTN X2, (0.25 mm tip and $6 \%$ taper) and is run by a clockwise (CW) continuous rotation [10].

The S-one Plus Single NiTi Reciprocation File (Foshan Soco Precision Instrument Co.,Ltd) is a single file which is more flexible than the traditional single file 
and have a good variable pitch design for quick and automatic removal of debris to the crown side, variable pitch design and S-section enhance transverse cutting force, to complete the preparation with unusual sharp section and enhance the capacity to evacuate the chip.

Wave one gold (WOG) Primary $(25,0.07)$ variable taper with a parallelogram cross section with two cutting edges in contact with the canal wall, alternating with an off-centered cross section. It rotates in a reciprocal motion, with preset values set by the manufacturer in clockwise/counter-clockwise angles, counterclockwise which is greater than clockwise allows the file to progress apically while the latter disengages the file and eliminates file binding [11].

The cleaning and shaping efficacy of the newly introduced $\mathrm{NiTi}$ rotary system should be thoroughly investigated to provide endodontists with a reliable recommendation for improving root canal treatment outcomes [12].

This study aimed to assess the cleaning efficacy of single-file systems, such as Trunatomy $26 / 0.04 \%$, Protaper Next $25 / 0.06 \%$ in full rotation motion and in reciprocating motion S-one plus $25 / 0.06 \%$, and Wave one gold $25 / 0.07 \%$, using a serial scanning electron microscope at various magnifications.

\section{Materials and Methods}

A total of 80 single-rooted lower premolars teeth were selected for this study and put in thymol 0.1 percent immediately after extraction for orthodontic reasons. The inclusion criteria were morphological resemblance, single-canal roots, straight roots, absence of root caries, absence of previous endodontic treatment, and periapical lesion.

\section{Root canal instrumentation}

A carborundum diamond disc $(D+Z$, Diamond, Germany) was used to remove the crown of each tooth at the level of the cementum-enamel junction (CEJ) (Fig. 1) to create root segments of approximately 15 $\mathrm{mm}$ in length [13], before root canal preparation, the patency of the root canal was determined by inserting a hand K-file \#10 into the apical foramen. Two mm of root apexes were sealed with melted beading wax (Associated Dental Products Ltd; Wiltshire, UK) and polyvinyl siloxane PVS (Zhermack SpA, Badia Polesine, Italy) impression material using a plastic ice mold, each mold consisted of 15 parts of $(2 \times 2)$ in diameter to access the instrumentation, then divided into four experimental groups, each with 20 roots [14].

Group 1;TruNatomy and Group 2; Protaper Next:The files were used in full rotation with a 6:1

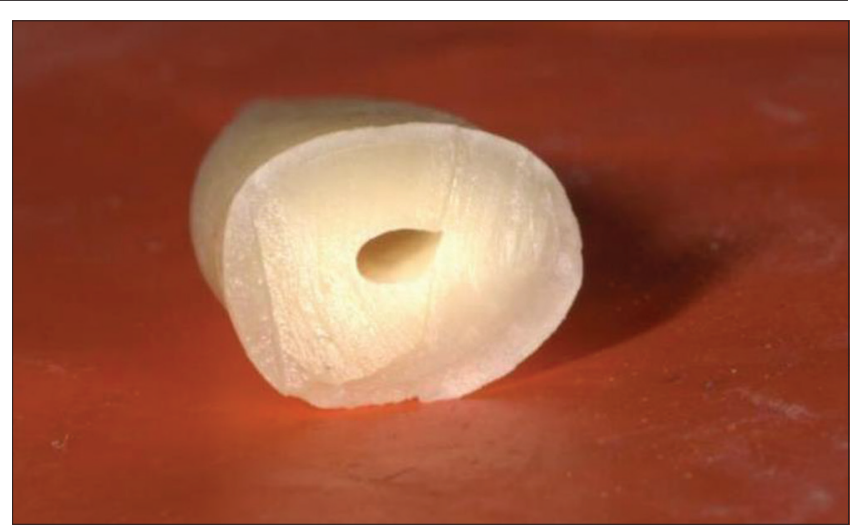

Figure 1: Tooth crown was removed at the level of the cementum-enamel junction by a carborundum diamond disc ( $D+Z$, Diamond, Germany)

contra-angle handpiece (Sirona, Bensheim, Germany) powered by a torque-limited an electric motor (VDW gold Reciproc motor; VDW GmbH, München, Germany) according to the manufacturer's instructions. The roots were instrumented in group one (500 rpm, torque 1.5) and in group two ( $300 \mathrm{rpm}$, maximum torque $2.5 \mathrm{~N} / \mathrm{cm}$ ) in crown down technique [15], in-and-out pecking motions and a side-to-side/up-and-down motion [16]. Intermittently, three to four times, the file was used in a slight lifting motion while stroking, to facilitate outward removal of debris, with each stroke the file was reinserted exerting a buccal to lingual cutting pressure on the out-stroke [13].

In Group 3; S-one Plus and Group 4; Wave one gold: They were used in a reciprocating motion, slow in-and-out pecking motions and a side-to-side/up-anddown motion with the dedicated reciprocating motor (Gold Reciproc, VDW) according to the manufacturer configuration setup. The flutes of the instrument were cleaned after 3 in and out movements [13].

In all groups, individual instruments were discarded after use in each root canal and irrigation was performed after each pecking motion during instrumentation using disposable syringes and 30-gauge needles, with a side vent that had been placed down the canal until slight resistance was felt [17].

In all experimental groups, $5.25 \%$ sodium hypochlorite and $15 \%$ EDTA, were used as per the manufacturer's instructions during a sequential crown down instrumentation technique [4]. Irrigation protocol was $1.0 \mathrm{ml}$ normal saline followed by $2.0 \mathrm{ml}$ of 5.25 $\% \mathrm{NaOCl}$ solution after every pecking motion and kept flooded with irrigant during the instrumentation phase, then $1.0 \mathrm{ml}$ of $15 \%$ EDTA solution left for $1 \mathrm{~min}$ and a final rinse with $1.0 \mathrm{ml}$ saline to neutralize the action of the irrigating agents [18].

A gutta-percha cone (ProTaper F2) was inserted into the canal as an indication for determining the longitudinal groove depth without perforating the canal for scanning electron microscopy analysis [19]. This precaution was adopted to prevent the cutting disc from splattering cutting debris into the canals, potentially contaminating the specimens [14]. A diamond disc ( $D+Z$, 
Diamond, Germany) was used to create two longitudinal grooves on the lingual and buccal sides of each root to assist vertical splitting with a chisel (Fig.2: A and B) [4].

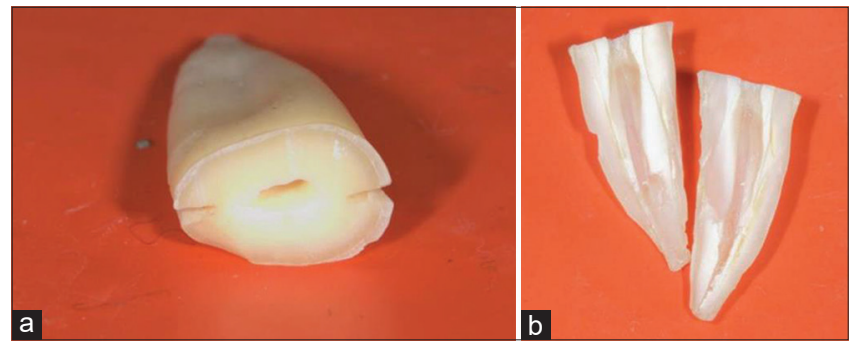

Figure 2: (a) Two longitudinal grooves were prepared on the lingual and buccal surfaces of each root with a diamond disc $(D+Z$, Diamond, Germany). (b) Splitting of the prepared root with a chisel

\section{Preparation of SEM}

The preparation of the samples took less than one hour. First, a very thin gold layer was deposited on the teeth by DC sputtering method. The thickness of the gold film was around $20 \mathrm{~nm}$, and the deposition rate was $2 \mathrm{~nm} / \mathrm{min}$. Then, the specimens were examined under Scanning Electron Microscope, the SEM imaging (MV2300, VEGA, TESCAN) was carried out at $30 \mathrm{KV}$ for assessment of the microscopic pattern of magnification and a standardized series of three photomicrographs each was taken for comparison in the apical, middle and coronal thirds of the canal at X200 for debris and X1000 for the smear layer. Using the scanned images, two trained observers conducted separate blind evaluations for the remaining debris and smear layer.

The smear layer and the surface debris were each given a standardized semi-quantitative evaluation in four classes, according to the classification [20]. The following were the scoring criteria:

A score of superficial debris : score 1: little or no superficial debris covering up to $25 \%$ of the specimen; score 2: little to moderate debris covering between 25 and $50 \%$ of the specimen; score 3 :moderate to heavy debris covering between 50 and $75 \%$ of the specimen; and score 4: heavy amount of aggregated or scattered debris over $75 \%$ of the specimen.

A score of the smear layer was as follow, score 1: little or no smear layer; covering less than $25 \%$ of the specimen; tubules visible and patent; score 2: little to moderate or patchy amounts of smear layer; covering between 25 and $50 \%$ of the specimen; many tubules visible and patent; score 3: moderate amounts of scattered or aggregated smear layer; covering between $50 \%$ and $75 \%$ of the specimen; minimal to no tubule visibility or patency, and score 4: heavy smear layering covering over $75 \%$ of the specimen; no tubule orifices visible or patent [21]. The Kruskal-Wallis test and the Mann-Whitney test were used to statistically examine the data from the scanning electron microscopic images, and the level of statistical significance was at $p<0.05$.

\section{Results}

\section{Smear layer}

Table 1and Fig. 3 show that there were no significant differences in smear layer removal between Trunatomy and Wave One Gold, Trunatomy removes the smear layer substantially better than PTN and S-one Plus. Wave one gold significantly removes smear layer better PTN. Furthermore, there was no significant difference between PTN and S-one Plus, S-one Plus and Wave One Gold.

Table 1: Summary of scores of smear layers of the prepared canals

\begin{tabular}{lllll}
\hline Experimental groups & Mean \pm ED & Mean \pm ED & p-value \\
\hline Trunatomy & PTN & $2.12 \pm 0.99$ & $2.8 \pm 1.07$ & $0.000^{*}$ \\
Trunatomy & S-One Plus & $2.12 \pm 0.99$ & $2.67 \pm 0.91$ & $0.003^{*}$ \\
Trunatomy & Wave One Gold & $2.12 \pm 0.99$ & $2.4 \pm 0.99$ & 0.12 \\
PTN & S-One Plus & $2.8 \pm 1.07$ & $2.67 \pm 0.91$ & 0.464 \\
PTN & Wave One Gold & $2.8 \pm 1.07$ & $2.4 \pm 0.99$ & $0.029^{*}$ \\
S-One Plus & Wave One Gold & $2.67 \pm 0.91$ & $2.4 \pm 0.99$ & 0.143 \\
\hline \multicolumn{2}{r}{ "The mean difference is significant at the 0.05 level, PTN: ProTaper next. }
\end{tabular}

Fig. 3 shows scanning electron microscope scans of canal wall after preparation with rotary $\mathrm{NiTi}$ instruments in middle third. Trunatomy group: Slight smear layer with mostly open dentinal tubules (score 1 magnification 1000X). PTN group: Smear layer with some open dentinal tubules (score 2 magnification 1000X). S-one Plus group: Slight smear layer with mostly open dentinal tubules (score 1 magnification 1000X). WOG group: Slight smear layer with mostly open dentinal tubules (score 1 magnification 1000X).

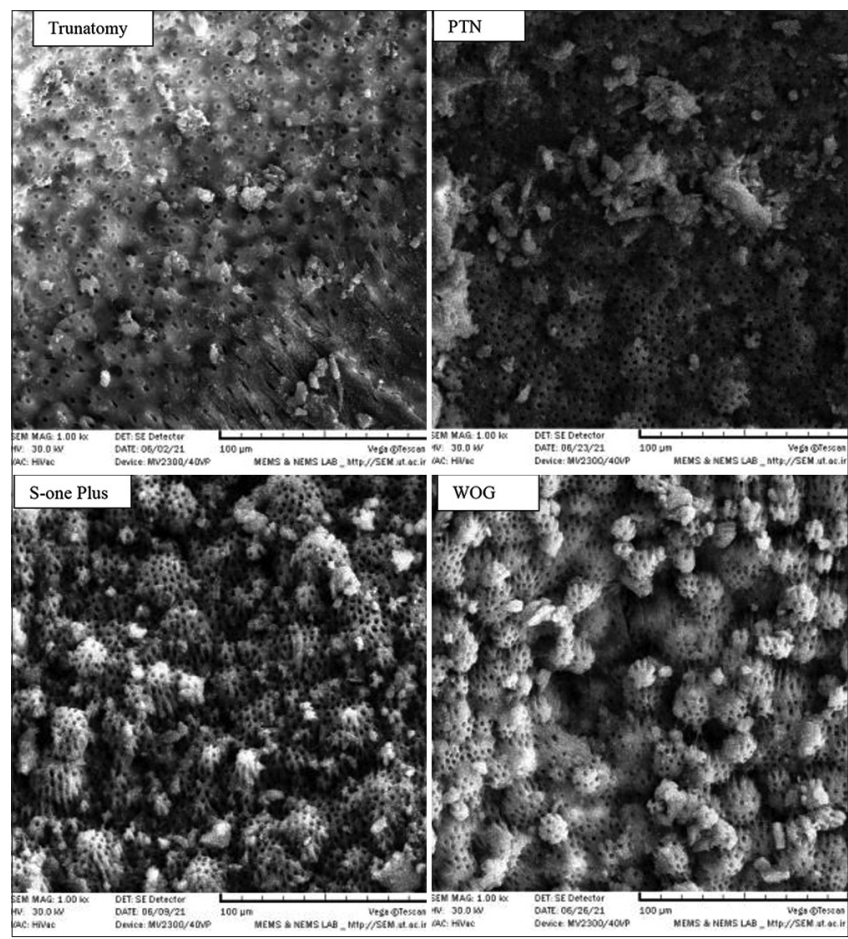

Figure 3: Root dentinal tubules after instrumentation with Trunatomy, ProTaper next, S-One Plus and Wave One Gold file 1000× for Smear layer

Table 2 and Fig. 4 show that Trunatomy significantly removes in the smear layer better than 
Table 2: Intergroup comparison of mean debris removal scores at coronal, middle, and apical third

\begin{tabular}{llllll}
\hline \multicolumn{2}{l}{ Inter group comparison } & \multicolumn{3}{l}{ Smear layer } \\
\cline { 3 - 6 } & & Apical & Middle & Coronal & Total \\
\hline Trunatomy & PTN & 0.242 & $0.021^{*}$ & $0.014^{*}$ & $0.000^{*}$ \\
Trunatomy & S-One Plus & 0.301 & $0.060^{*}$ & $0.003^{*}$ & $0.003^{*}$ \\
Trunatomy & Wave One Gold & 0.820 & 0.231 & 0.052 & 0.120 \\
PTN & S-One Plus & 0.758 & 0.369 & 0.820 & 0.464 \\
PTN & Wave One Gold & 0.134 & 0.157 & 0.495 & 0.290 \\
S-One Plus & Wave One Gold & 0.192 & 0.495 & 0.547 & 0.143 \\
\hline
\end{tabular}

PTN and S-One Plus in the middle and coronal thirds, while there was no significant difference between other groups in smear layer removal in apical, middle and coronal thirds.

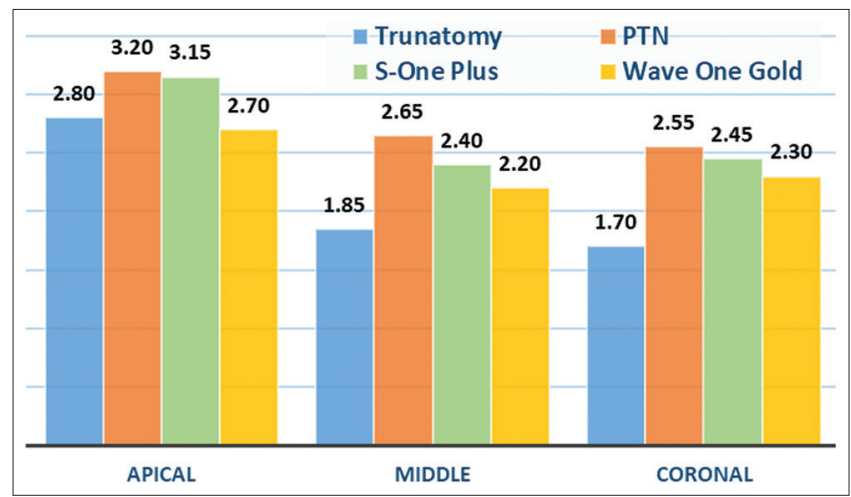

Figure 4: Bar graph shows summary of the scores of smear layer in three regions of the prepared canals

\section{Debris layer}

Table 3 and Fig. 5 show that the Trunatomy file significantly removed the debris layer better than all other groups. There were significant differences between all groups except PTN and S-one Plus, as well as between S-One Plus and Wave One Gold.

\section{Table 3: Summary of scores of debris of the prepared canals}

\begin{tabular}{lllll}
\hline Experimental groups & Mean \pm ED & Mean \pm ED & p-Value \\
\hline Trunatomy & PTN & $1.95 \pm 0.96$ & $2.65 \pm 0.89$ & $0.000^{*}$ \\
Trunatomy & S-One Plus & $1.95 \pm 0.96$ & $2.48 \pm 0.91$ & $0.002^{*}$ \\
Trunatomy & Wave One Gold & $1.95 \pm 0.96$ & $2.30 \pm 0.91$ & $0.038^{*}$ \\
PTN & S-One Plus & $2.65 \pm 0.89$ & $2.48 \pm 0.91$ & 0.322 \\
PTN & Wave One Gold & $2.65 \pm 0.89$ & $2.30 \pm 0.91$ & $0.038^{*}$ \\
S-One Plus & Wave One Gold & 2.48 \pm 0.91 & $2.30 \pm 0.91$ & 0.277 \\
\hline
\end{tabular}

Fig. 5 show scanning electron microscope scans of canal wall after preparation with rotary NiTi instruments in middle third. Trunatomy group: Slight debris layer with mostly open dentinal tubules (score 1 magnification 200X). PTN group: debris layer with some open dentinal tubules (score 2 magnification 200X).

Table 4: Intergroup comparison of mean debris removal score at coronal, middle, and apical thirds

\begin{tabular}{llllll}
\hline \multirow{2}{*}{ Inter group comparison } & \multicolumn{3}{l}{ Debris removal $(\mathrm{p}$ value $)$} \\
\cline { 3 - 6 } & & Apical & Middle & Coronal & Total \\
\hline Trunatomy & PTN & $0.028^{*}$ & $0.006^{*}$ & $0.009^{*}$ & $0.008^{*}$ \\
Trunatomy & S-One Plus & 0.081 & $0.012^{*}$ & 0.052 & $0.020^{*}$ \\
Trunatomy & Wave One Gold & 0.602 & 0.081 & $0.018^{*}$ & $0.038^{*}$ \\
PTN & S-One Plus & 0.620 & 0.495 & 0.512 & 0.322 \\
PTN & Wave One Gold & $0.011^{*}$ & 0.289 & 0.947 & $0.038^{*}$ \\
S-One Plus & Wave One Gold & $0.038^{*}$ & 0.583 & 0.495 & $0.027^{*}$ \\
\hline \multicolumn{2}{l}{ *The mean difference is significant at the 0.05 level, PTN: ProTaper next. }
\end{tabular}
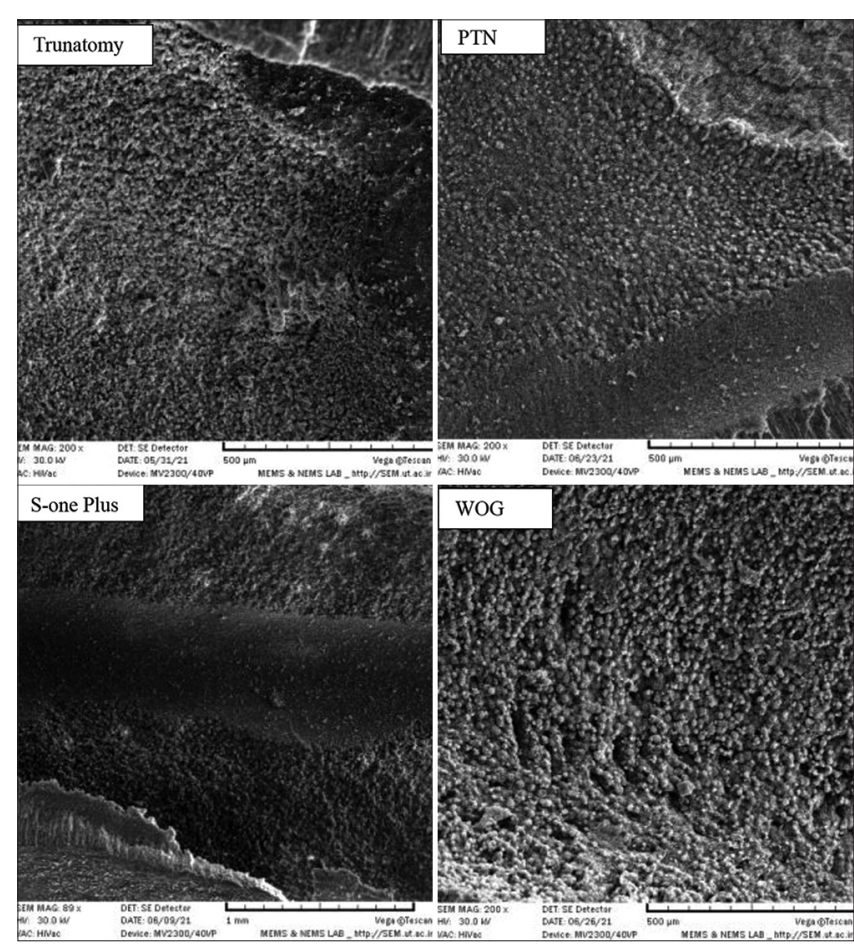

Figure 5: Root dentinal tubules after instrumentation with Trunatomy, ProTaper next, S-One Plus, and Wave One Gold file 200× for debris layer.

S-one Plus group: Slight debris layer with mostly open dentinal tubules (score 1 magnification 200X). WOG group: Slight debris layer with mostly open dentinal tubules (score 1 magnification 200X).

Table 4 and Fig. 6 show that Trunatomy significantly removes the debris layer better than PTN file in all root thirds, also Trunatomy significantly removes the debris layer better than S-one plus in the middle third and better than Wave One Gold in the coronal third only, while WOG removes the debris layer significantly better than PTN and S-One Plus in the apical third. However, there was no significant difference between PTN and S-one Plus in debris removal in all root thirds.

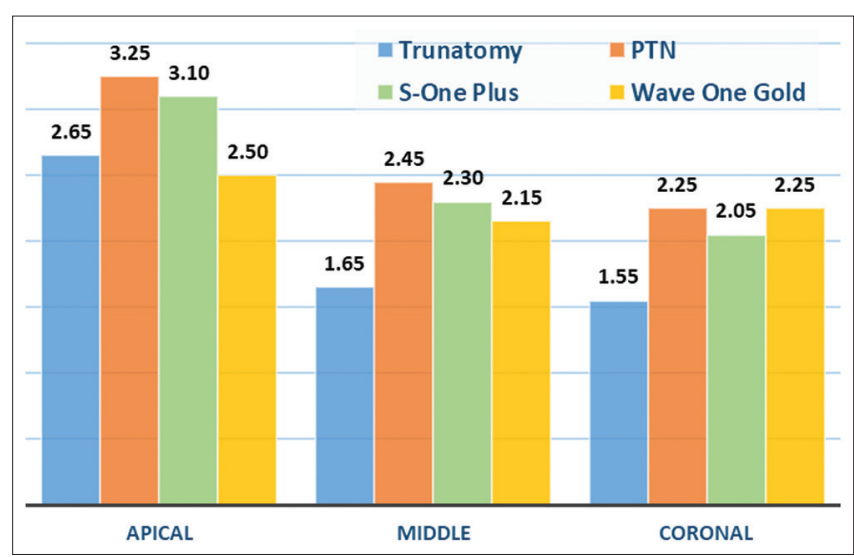

Figure 6: Bar graph shows summary of the scores of the debris layer in three regions of the prepared canal 


\section{Discussion}

The removal of vital and necrotic pulp tissue, dentin debris, and infected dentin is one of the most important goals of root canal instrumentation to eliminate the majority of bacteria from the root canal system [8] in order to allow the root filling to adapt closely to the canal walls, mechanical instrumentation on the other hand, was developed to allow for successful cleaning and shaping while avoiding excessive loss of sound dentin, perhaps leading to minimally invasive endodontic therapy [16].

The influence of endodontic instruments on the morphology of dentin surfaces appears to be well investigated using SEM examination [22]. SEM provides high-resolution pictures that enable the study of debris and smear layer-covered areas, as well as the detection of patent dentinal tubules [23]. However, there is no agreement on how to standardize debris and smear layer measurements. In this research, micrographs at higher magnifications $1000 \mathrm{X}$ were used to evaluate the smear layer on the root surface and dentinal tubules, whereas 200X magnification was utilized to evaluate the debris layer on the root canal surfaces [4] [24].

Previous research has shown that neither instruments nor techniques can entirely clean canal walls; our findings support the previous research finding, demonstrating that none of the instruments or operating principles used could completely clean (smear and debris-free root) canal surfaces [16].

On the basis of the findings, the removal of debris and smear layers is not only depend on the irrigation method and type, but also on the design of the endodontic file (size, taper, cross-section, and so on), as well as how the instrument is used (rotational or reciprocal) [25].

Tables 1 and 3 show that Trunatomy system resulted in the formation of less amount smear layer and debris compared to other systems, it seems that this ability is due to the unique design of Trunatomy files, slim NiTi wire design with $0.8 \mathrm{~mm}$ maximum flute diameter,with generic progressive tapered file had variable taper ensuring that the shank ends up again with a maximum flute diameter of $0.8 \mathrm{~mm}$, these files have a off-centred parallelogram cross-sections, active cutting flutes, this design helps reduce the risk of obstruction of the pathway and minimizes the accumulation of smear and dentinal chips [26].

Wave One Gold came in second place after TruNatomy in terms of producing better results than S-one Plus and ProTaper Next, which are in agreement with Feghali et al., 2019, who concluded that Wave One Gold showed better results in term of cleanliness [27]. While contradicts with the findings of Al-Khafaji and Al-Huwaizi in 2019, Ismail et al., 2019 [28] [29] which they concluded that ProTaper Next showed less average means of smear layer and debris layer compared to WaveOne Gold.

Wave One Gold's cross-section is a parallelogram with two 85-degree cutting edges in contact with the canal wall, alternating with an offcentred cross-section with only one cutting edge in contact with the canal wall, reducing the contact area between the file and the canal wall and, combined with a constant helical angle of 24 degrees along the active length of the instrument, ensuring little or no screwing in [30].

Although, S-one Plus and ProTaper have more smear layer and debris development compared to TruNatomy, which could be due to S-one Plus had a variable pitch design, $S$ shaped cross-section, deep flutes, and the distance between the cutting blades increased from the file tip to the shank with transverse cutting force.

However, ProTaper Next system were designed so that the center of mass and the center of rotation are off-set. This feature generates a mechanical wave of motion that travels along the active length of the file and provides a better reduction of the engagement between the file and dentin [31]. These files' lower cutting capacity and higher smear layer and debris accumulation are thought to be due to their offcentered rectangular cross-section, which causes the file to "swagger" as it goes through the root canal [32].

On the other hand, the efficacy of the working motion of the files selected reciprocating motion and full clockwise rotation motion- in terms of root canal wall cleanliness was compared. Trunatomy with full rotation and Wave One Gold with reciprocating showed the best performance in cleanliness in comparison to other instruments, as a result this could be explained that the kinematics of the instruments did not affect the cleaning capacity, preparation with reciprocating or complete rotation resulted in equivalent efficacy in terms of smear and debris layer removal, this finding are in agreement with Ismail, et al., 2019 finding [29].

While disagreeing with a previous finding by Robinson et al., 2013; Poggio et al., 2014, they found more smear and debris layer in the apical areas of root canals prepared by reciprocating instruments compared to instruments operated in continuous rotation[33][13]. The results of this study also disagree with AI-Khafaji and Al-Huwaizi, 2019 who found that continuous rotation produced a higher smear layers in the apical third, but there were no significant differences in smear and debris layers in the other thirds [28] .

All experimental files in tables 2 and 4 showed significant levels of cleanliness and smear layer reduction at the coronal and middle thirds compared to the apical, which come agreement with previous research findings Vincenzi et al., 2011 [34], However it disagrees with Ibrahim et al., 2019 who concluded experimented files failed to remove the smear layer in 
the coronal, middle, and apical thirds with no significant difference between the three levels [7]

Although the tested files have different tapers, an increase in the taper from $4 \%$ to $7 \%$ did not significantly reduce the residual debris and smear layer in the apical third, all files were effective in cleaning the root canal surfaces at the coronal and middle thirds as shown in Tables 2 and 4, this findings are in agreement with Schäfer and Zapke, 2000; Arvaniti and Khabbaz, 2011; Zarei et al., 2016; Feghali et al., 2019; Andreani et al., 2021[23][35][27][36] [37], who reported that an increase in taper associated with an apical size 30 did not affect the amount of smear layer in the apical third. On the other hand disagreeing with Plotino et al., 2019 who concluded in their study that 0.04 taper removed less smear and debris layer in the apical third compared to the middle and coronal thirds [38].

\section{Conclusion}

Completely clean root canals were not found after instrumentation with any of the examined rotary files. TruNatomy showed better cleaning capacity than the other groups. All files demonstrated better cleanliness at the coronal and middle third compared to the apical third.

\section{Acknowledgment}

The authors would like to gratefully acknowledge the support from the MEMS Lab at the University of Tehran for SEM and Behin Negareh Company, Tehran, Iran, for image processing.

\section{References}

1. Tomson PL, Simon SR. Contemporary cleaning and shaping of the root canal system. Prim Dent J. 2016;5(2):46-53. https://doi. org/10.1308/205016816819304196

PMid:28826433

2. El-Kishawi M, Khalaf K. An update on root canal preparation techniques and how to avoid procedural errors in endodontics. Open Dent J. 2021;15:318-24. https://doi. org/10.2174/1874210602115010318

3. Taha NA, Maghaireh GA, El Sadek D, Bagheri R, Al-Omari M. Shaping ability of thermomechanically treated files in simulated S-shaped root canals. Open J Stomatol. 2013;3(7):386-91. https://doi.org/10.4236/ojst.2013.37065

4. Shetty S, Hegde MN, Devadiga D. A scanning electron microscopic study of debris and smear layer remaining following use of greater taper rotary instruments. Res J Pharm Biol Chem Sci. 2013;4:177-87. https://doi.org/10.4103/2231-0754.115780

5. Nathani TI, Nathani Al, Pawar AM, Khakiani MI, Ruiz XF, Olivieri JG. Canal transportation and centering ability in long oval canals: A multidimentional analysis. J Endod. 2019;45(10):1242-7. https://doi.org/10.1016/j.joen.2019.07.007 PMid:31472950

6. Hulsmann M, Peters OA, Dummer PM. Mechanical preparation of root canals: Shaping goals, techniques and means. Endod Top. 2005;10(19):30-76. https://doi. org/10.1111/j.1601-1546.2005.00152.x

7. Ibrahim S, Bayoumi A, Hassanein E. Comparative analysis of the cleaning ability of single file versus multiple file system (An in vitro study). Egypt Dent J. 2019;65(4):3601-6. https://doi. org/10.21608/edj.2019.75978

8. Kiran S, Prakash S, Siddharth PR, Saha S, Geojan NE Ramachandran M. Comparative evaluation of smear layer and debris on the canal walls prepared with a combination of hand and rotary proTaper technique using scanning electron microscope. J Contemp Dent Pract. 2016;17(7):574-81. https:// doi.org/10.5005/jp-journals-10024-1892 PMid:27595725

9. Elnaghy AM, Elsaka SE, Mandorah AO. In vitro comparison of cyclic fatigue resistance of TruNatomy in single and double curvature canals compared with different nickel-titanium rotary instruments. BMC Oral Health. 2020;20(1):38. https://doi. org/10.1186/s12903-020-1027-7

PMid:32019522

10. Ismail AG, Zaazou MH, Galal M, Kamel NO, Nassar MA. Finite element analysis comparing WaveOne gold and ProTaper next endodontic file segments subjected to bending and torsional load. Bull Natl Res Cent. 2019;43:6-11. https://doi.org/10.1186/ s42269-019-0215-6

11. Adıgüzel M, Capar ID. Comparison of cyclic fatigue resistance of WaveOne and WaveOne gold small, primary, and large instruments. J Endod. 2017:43(4):623-7. https://doi. org/10.1016/j.joen.2016.11.021

PMid:28216272

12. Hülsmann $M$, Rümmelin $C$, Schäfers $F$. Root canal cleanliness after preparation with different endodontic handpieces and hand instruments: A comparative SEM investigation. J Endod. 1997;23(5):301-6. https://doi.org/10.1016/ S0099-2399(97)80410-4 PMid:9545932

13. Poggio C, Dagna A, Chiesa $M$, Scribante A, Beltrami $R$, Colombo M. Effects of NiTi rotary and reciprocating instruments on debris and smear layer scores: An SEM evaluation. J Appl Biomater Funct Mater. 2014;12(3):256-62. https://doi. org/10.5301/jabfm.5000161 PMid:24425380

14. Alakshar A, Saleh AR, Gorduysus MO. Debris and smear layer removal from oval root canals comparing XP-endo finisher, endoactivator, and manual irrigation: A SEM evaluation. Eur J Dent. 2020;14(4):626-33. https://doi. org/10.1055/s-0040-1714762 PMid:32777834

15. Roghanizad N, Vatanpour M, Eslami LM, Bahrami $H$ Comparison of WaveOne and ProTaper universal preparation systems in the amount of smear layer/debris production: An in-vitro SEM study. J Res Dent Maxillofac Sci. 2017;2:33-43. https://doi.org/10.29252/jrdms.2.4.33

16. Koçak MM, Saglam BC, Türker SA. Smear layer and debris removal following use of waveone and oneshape single-file systems: SEM study. Int J Exp Dent Sci. 2014;3(2):77-83. https://doi.org/10.5005/jp-journals-10029-1076

17. Drukteinis S, Balciuniene I. A scanning electron microscopic 
study of debris and smear layer remaining following use of AET instruments and K-flexofiles. Stomatologija. 2006;8(3):70-5. PMid:17191061

18. Gambarini G. Shaping and cleaning the root canal system: A scanning electron microscopic evaluation of a new instrumentation and irrigation technique. $\mathrm{J}$ Endod. 1999;25(12):800-3. https://doi.org/10.1016/ S0099-2399(99)80300-8

PMid:10726524

19. Mancini M, Cerroni L, lorio L, Armellin E, Conte G, Cianconi L. Smear layer removal and canal cleanliness using different irrigation systems (EndoActivator, EndoVac, and passive ultrasonic irrigation): Field emission scanning electron microscopic evaluation in an in vitro study. $\mathrm{J}$ Endod. 2013;39(11):1456-60. https://doi.org/10.1016/j.joen.2013.07.028 PMid:24139274

20. Gutmann JL, Saunders WP, Nguyen L, Guo IY, Saunders EM. Ultrasonic root-end preparation Part 1. SEM analysis. Int Endod J. 1994;27(6):318-24. https://doi.org/10.1111/j.1365-2591.1994. tb00276.x

PMid:7751066

21. de Oliveira Kublitski PM, Tomazinho FS, Marques-da-Silva B, dos Santos VR, da Silva WJ, Baratto-Filho F, et al. Cleaning of long oval canals with WaveOne gold system associated with different irrigant agitation protocols. Brazilian J Oral Sci. 2021;21:1-11. https://doi.org/10.20396/bjos.v21i00.8664013

22. Ahlquist $M$, Henningsson $O$, Hultenby $K$, Ohlin J. The effectiveness of manual and rotary techniques in the cleaning of root canals: A scanning electron microscopy study. Int Endod J. 2001;34(7):533-7. https://doi. org/10.1046/j.1365-2591.2001.00429.x

PMid:11601771

23. Arvaniti IS, Khabbaz MG. Influence of root canal taper on its cleanliness: A scanning electron microscopic study. J Endod. 2011;37(6):871-4. https://doi.org/10.1016/j.joen.2011.02.025 PMid:21787508

24. Saraf AA, Patil AC, Mangala TM, Mahaparale R, Mali S, Pawar S. Comparison of cleaning effectiveness of single rotary file OneShape and reciprocating F2 protaper with protaper universal sequence: A SEM analysis. J Oral Biol Craniofacial Res. 2020;10(4):337-42. https://doi.org/10.1016/j. jobcr.2020.06.011

PMid:32714786

25. Jadhav GR, Mittal P, Kulkarni A, Syed S, Bagul R, Elahi S, et al. Comparative evaluation of canal cleaning ability of various rotary endodontic filesin apical third: A scanning electron microscopic study. Dent Res J (Isfahan). 2016;13(6):508-14. https://doi. org/10.4103/1735-3327.197031

PMid:28182065

26. van der Vyver PJ, Vorster M, Peters OA. Minimally invasive endodontics using a new single-file rotary system. Int Dent Afr Ed. 2019;9:6-20.

27. Feghali M, Jabbour E, Koyess E, Sabbagh J. Scanning electron microscopy evaluation of debris and smear layer generated by two instruments used in reciprocating motion WaveOne Gold $\circledast$ and Reciproc Blue®. Aust Endod J. 2019;45(3):388-93. https:// doi.org/10.1111/aej.12338

PMid:30770606

28. Al-Khafaji $\mathrm{H}, \mathrm{Al}-\mathrm{Hu}$ waizi $\mathrm{H}$. Cleaning Efficiency of Root Canals using Differ ent Rotary Instrumentation Systems: A Comparative In Vitro Study; 2019. Available from: https://wwwijmrhscom/ abstract/cleaning-efficiency-of-root-canals-using-differ-entrotary-instrumentation-systems-a-comparative-in-vitro-study15506html [Last accessed on 2021 Nov 21].

29. Ismail AG, Nagy MM, Galal M. Cleaning ability of rotary $\mathrm{NiTi}$ systems with different kinematics. Bull Natl Res Cent. 2019;43:197. https://doi.org/10.1186/s42269-019-0191-x

30. Webber J. Shaping canals with confidence: WaveOne GOLD single-file. Roots Int Dent Afr Ed. 2015;6:34-40.

31. Elnaghy AM, Elsaka SE. Assessment of the mechanical properties of ProTaper next nickel-titanium rotary files. J Endod. 2014;40(11):1830-4. https://doi.org/10.1016/j.joen.2014.06.011 PMid:25129026

32. van der Vyver P, Vorster M, Paleker F, de Wet F. Root canal preparation: A literature review and clinical case reports of available materials and techniques. South Afr Dent J. 2019;74:246-54. https://doi.org/10.17159/2519-0105/2019/ v74no4a4

33. Robinson JP, Lumley PJ, Cooper PR, Grover LM, Walmsley AD. Reciprocating root canal technique induces greater debris accumulation than a continuous rotary technique as assessed by 3-dimensional micro-computed tomography. J Endod. 2013;39(8):1067-70. https://doi.org/10.1016/j.joen.2013.04.003 PMid:23880279

34. Vincenzi V, Plotino G, Giansiracusa A, Pietrangeli E, Al Sudani D, Grande NM, et al. A SEM study of canal cleanliness after a new nickel-titanium rotary instrumentation technique. Ann Stomatol (Roma). 2011;2(1-2):19-22. PMid:22238718

35. Zarei M, Javidi M, Afkhami F, Tanbakuchi B, Zadeh MM, Mohammadi MM. Influence of root canal tapering on smear layer removal. NY State Dent J. 2016;82(3):35-8. PMid:27348950

36. Andreani Y, Gad BT, Cocks TC, Harrison J, Keresztes ME, Pomfret JK, et al. Comparison of irrigant activation devices and conventional needle irrigation on smear layer and debris removal in curved canals. (Smear layer removal from irrigant activation using SEM). Aust Endod J. 2021;47(2):143-9. https:// doi.org/10.1111/aej.12482

PMid:33682268

37. Schäfer E, Zapke K. A comparative scanning electron microscopic investigation of the efficacy of manual and automated instrumentation of root canals. J Endod. 2000;26(11):660-4. https://doi.org/10.1097/00004770-200011000-00007 PMid:11469296

38. Plotino G, Özyürek T, Grande NM, Gündoğar M. Influence of size and taper of basic root canal preparation on root canal cleanliness: A scanning electron microscopy study. Int Endod J. 2019;52(3):343-51. https://doi.org/10.1111/iej.13002 PMid:30129186 